\title{
Effects of Ginsenosides on Microvascular and Immune Microenvironment and Prognosis of Hepatocellular Carcinoma
}

\author{
YULAN WANG, JING CAI ${ }^{1}$, ZHENGJUN LI², JIANPING LI³, GUANGMEI CHEN, SIQING CHEN, SHUJIE LI'4, ZHENG YUAN \\ AND PENG SHU5*
}

Department of Infectious Diseases, Affiliated Hospital of Nanjing University of Chinese Medicine, Nanjing, Jiangsu 210029, ${ }^{1}$ Department of Oncology and Hematology, The First People's Hospital of Longquanyi District, Chengdu, Sichuan 610100, ${ }^{2}$ Department of Radiology, Affiliated Hospital of Nanjing University of Chinese Medicine, Nanjing, Jiangsu 210029, ${ }^{3}$ Department of Medical Oncology, Yancheng No. 1 People's Hospital, Yancheng, Jiangsu 224006, ${ }^{4}$ Department of Traditional Chinese Medicine, Fujian Medical University Union Hospital, Fuzhou, Fujian 350001, ${ }^{5}$ Department of Oncology, Affiliated Hospital of Nanjing University of Chinese Medicine, No. 155 Hanzhong Road, Nanjing, Jiangsu 210029, China

Wang et al.: Effects of Ginsenosides on Hepatocellular Carcinoma

\begin{abstract}
To investigate the effects of ginsenosides on the microvascular and immune microenvironment of hepatocellular carcinoma rats and analyzes the relationship on the prognosis of patients with hepatocellular carcinoma. 60 patients with hepatocellular carcinoma were collected and randomly divided into control and treatment group in our hospital from January 2018 to January 2020 and clinical symptoms improvement and adverse reactions were compared and analyzed. 60 rats were randomly divided into ginsenoside, control and model group. The immune cell infiltration and microvascular density were detected and analyzed. In animal studies, the infiltration of cluster of differentiation $3^{+}$, cluster of differentiation $4^{+}$, cluster of differentiation $8^{+}$and forkhead box $\mathrm{P3}^{+} \mathrm{T}$ lymphocytes increased significantly while the transforming growth factor beta 1 value decreased significantly after treatment with ginsenoside. Clinically, the patients in the treatment group showed significant improvement in their conscious symptoms and higher treatment efficiency while the adverse reactions such as decrease of white blood cell, decrease of hemoglobin, decrease of platelet, nausea and vomiting and low fever than that of in control group. In hepatocellular carcinoma model, ginsenosides induced lymphocyte infiltration and inhibited tumor angiogenesis to exert anti-tumor effects. And ginsenoside has both anti-tumor and quality of life effects and has good efficacy in the treatment of advanced primary hepatocellular carcinoma.
\end{abstract}

Key words: Ginsenoside, hepatocellular carcinoma, immune cells, tumor

Hepatocellular Carcinoma (HCC) is one of the most common malignant tumors in the world, with high incidence rate and mortality rate ${ }^{[1]}$. Previous studies showed that the incidence rate of HCC in China ranks fourth of all malignant tumors and the mortality rate is third, which seriously threatens people's health ${ }^{[2]}$. Due to the occult onset, HCC is very difficult to be diagnosed in the early stage. At present, serum Alpha Fetoprotein (AFP) level and imaging examination are the most commonly used methods for the diagnosis of $\mathrm{HCC}^{[3,4]}$, but there are limitations, such as the diagnostic rate of AFP is about $70 \%$. In recent years, the progress of liquid biopsy technology makes the early diagnosis of tumor possible. As a component of tumor microenvironment, exosomes are ideal materials for liquid biopsy. Tumor Microenvironment (TME) is the environment in which tumor cells exist, including peripheral blood vessels, stromal cells, fibroblasts, immune cells, adipocytes, extracellular matrix and signal molecules ${ }^{[5]}$. These factors interact to form a complex and suitable microenvironment for tumor growth.

Ginsenoside $\mathrm{Rg} 3$ is one of the most important effective components in ginseng, which has been widely proved

*Address for correspondence

E-mail: shupengnjucm@163.com 
to have obvious anti-tumor effect ${ }^{[6-8]}$. In recent years, great breakthroughs have been made in the extraction process of $\mathrm{Rg} 3$ monomer in China and Shenyi capsule, a modern traditional Chinese medicine preparation, has been developed. After a series of clinical trials, it has been listed as a national first-class anticancer drug and can be used in the adjuvant treatment of lung cancer, HCC and other malignant tumors ${ }^{[9,10]}$. In order to further explore the anti-tumor invasion and metastasis effect of ginsenoside $\mathrm{Rg} 3$ and its related mechanism, we will explore the effect of Ginsenoside Rg3 on microvessel and immune microenvironment of hepatoma rats by establishing hepatoma rat model. In addition, the relationship between ginsenoside and prognosis of patients with HCC was further analyzed through clinical research.

\section{MATERIALS AND METHODS}

\section{General clinical data:}

A total of 60 patients with $\mathrm{HCC}$ in our hospital from January 2018 to January 2020 were selected and randomly divided into treatment group and control group. There were 30 patients in the treatment group, 18 males and 12 females, with a median age of $54 \mathrm{y}$; 17 patients in the clinical stage II and 13 patients in the stage III; 30 patients in the control group, 19 males and 11 females, with a median age of $56 \mathrm{y}$. There were 16 cases in stage II and 14 cases in stage III. The treatment group was treated with Shenyi capsule combined with Transarterial Chemoembolization (TACE), while the control group was treated with TACE alone. There was no significant difference in clinical data between the two groups $(\mathrm{p}>0.05)$. This study has been approved by the medical ethics committee of our hospital and the patients signed the informed consent.

\section{Therapeutic methods:}

Seldinger intubation was used for transcatheter arterial chemoembolization. After percutaneous femoral artery puncture, the guide wire was inserted first, then the catheter was inserted and the guide wire was withdrawn. After the location and scope of liver tumor were identified, chemotherapy drugs were injected through the catheter. 5-Fu needle $0.75 \sim 1.0$, HCTP needle 10 15 $\mathrm{mg}$, DDP needle 10 40 $\mathrm{mg}$ were injected into the hepatic artery first and then $40 \%$ iodine $10 \sim 15 \mathrm{ml}$ and MMC needle 10 15 mg were mixed into the hepatic artery for embolization. Two groups of patients were treated with the above two times, the interval of $1 \sim 2$ mo to review and repeat the above chemoembolization. The treatment group was treated with Shenyi capsule (produced by Jilin Yatai Pharmaceutical Co., Ltd.), twice a day for $60 \mathrm{~d}$, while the control group was treated with single interventional chemoembolization.

\section{Observation indexes:}

According to Response Evaluation Criteria In Solid Tumors (RECIST) curative effect standard, the curative effect was evaluated ${ }^{[2]}$ : Complete Remission (CR) includes complete disappearance of tumor lesions, maintained for more than $4 \mathrm{w}$; Partial Remission (PR) includes reduction of tumor lesions by more than 50 $\%$; stable (SD) includes reduction of tumor lesions by $50 \%$, no new lesions, maintained for more than $4 \mathrm{w}$; progress (PD) includes tumor lesions by more than 25 $\%$ or new lesions; The effective rate was calculated by $\mathrm{CR}+\mathrm{PR}$; clinical symptoms includes liver pain, abdominal distension, loss of appetite, fatigue and other symptoms were observed; Adverse reactions includes observe the changes of hemogram and gastrointestinal reactions.

\section{Animal experiment:}

60 healthy male Wistar rats (Nanjing Junke Bioengineering Co., Ltd.) weighing 174 225 g $(196.6 \pm 12.3) \mathrm{g}$ were selected and reared at $20^{\circ}$ and about $58 \%$ humidity for $12 \mathrm{~h}$ a d.

\section{Animal model construction:}

The mouse hepatoma cell line H22 (Nanjing Junke Bioengineering Co., Ltd.) from BABL/C was injected intraperitoneally with $0.2 \mathrm{ml}\left(1 \times 10^{7} / \mathrm{ml}\right)$. After $7 \mathrm{~d}$, the mice were killed and soaked in $75 \%$ alcohol for 1-2 min. Then the ascites were extracted, diluted with normal saline (NC) and centrifuged for precipitation. The tumor cell suspension of $1 \times 10^{7} / \mathrm{ml}$ was prepared with NC. Each mouse was subcutaneously inoculated with $0.2 \mathrm{ml}\left(2 \times 10^{6}\right)$ cells in the right armpit. The rats were randomly divided into normal group, model group and ginsenoside group.

\section{Medication treatment:}

The normal group and model group were only given normal saline once a day, while the ginsenoside group was given $105 \mathrm{mg} / \mathrm{kg} / \mathrm{d}$, with the volume of $0.5 \mathrm{ml} / 20$ g. The animals were given the medicine from the $2^{\text {nd }} d$ after modeling for 8 consecutive days.

\section{Immunohistochemical analysis:}

On the $14^{\text {th }} \mathrm{d}$ after treatment, all experimental animals were killed and the tumor area and surrounding tissue samples were collected, fixed with $4 \%$ formaldehyde, then embedded in paraffin and sectioned, with a 
thickness of $4 \mathrm{~mm}$. The Microvessel Density (MVD) was measured by using mouse anti-Cluster of Differentiation 31 (CD31) monoclonal antibody (Dako, Glostrup, Denmark). The positive expression of CD31 was observed by brown yellow granular staining in the cytoplasm and membrane of endothelial cells. The counting method was according to the method reported by Gasparini et al. and the average value was taken as the MVD value.

\section{Immunohistochemical detection of CD3, CD4, CD8 and Forkhead box P3 (FOXP3):}

The dilution of mouse Foxp3 monoclonal antibody (ebioscience company) was 1:1000; the dilution of CD3 monoclonal antibody (ebioscience company) was 1:1000; the dilution of CD4 and CD8 monoclonal antibody (ebioscience company) was 1:1000, Foxp3 was judged as positive cells by brown yellow staining of nucleus. 10 high power fields $(\times 200)$ were randomly selected to count positive cells and the average number of positive cells in each field was calculated. The results were expressed as "number of positive cells/hpf"

\section{Transforming growth factor beta 1 (TGF- $\beta 1$ ) level determination:}

Part of liver tissue was embedded in paraffin and sectioned. $5 \%$ Bovine Serum Albumin (BSA) solution was dripped and sealed for $15 \mathrm{~min}$ and then $50 \mu \mathrm{l}$ of primary antibody was dripped and allowed to stand at $37^{\circ}$ for $2 \mathrm{~h}$. After washing with PBS and drying, $50 \mu \mathrm{l}$ of secondary antibody was added and it was allowed to stand at $37^{\circ}$ for $20 \mathrm{~min}$. Rinse with distilled water, dry, add $50 \mu \mathrm{l}$ HRP-Streptavidin Conjugate (SABC) solution and let it stand at $37^{\circ}$ for $20 \mathrm{~min}$. After washing with distilled water and drying, 3,3'-Diaminobenzidine (DAB) solution was dripped to cover the surface of the slices. After standing for $5 \mathrm{~min}$ at room temperature, the tissue samples were immersed in hematoxylin solution for $10 \mathrm{~min}$, immersed in $95 \%$ ethanol solution for 5 min, immersed in anhydrous ethanol for $5 \mathrm{~min}$, repeated twice and then immersed in toluene solution for $5 \mathrm{~min}$ and dripped with a small amount of neutral gum and sealed to dry. Using MIAS-2000 pathological image analysis system analysis, under 400 times microscope observation, the cytoplasm or cell membrane is brown yellow can be judged as positive cells, using gray value to measure the staining intensity, the smaller the gray value represents the deeper the staining intensity, indicating the stronger the positive expression, randomly take 10 areas to calculate the positive gray value and finally take the average value.

\section{Statistical analysis:}

Statistical Package For The Social Sciences (SPSS) 20.0 software was used for statistical analysis. The measurement data were expressed as mean \pm standard deviation and Analysis Of Variance (ANOVA) was used for comparison between groups. $\mathrm{p}<0.05$ was considered statistically significant.

\section{RESULTS AND DISCUSSION}

Microvessels were mainly found around the tumor necrosis area. The MVD value of model group was significantly higher than that of control group $(\mathrm{p}<0.05)$. However, the MVD value of ginsenoside group was significantly lower than that of control group $(\mathrm{p}<0.05)$, as shown in fig. 1 .

As shown in fig. 2, the infiltration of $\mathrm{CD}^{+}, \mathrm{CD}^{+}$and $\mathrm{CD}^{+} \mathrm{T}$ lymphocytes in the ginsenoside treated group was significantly higher than that in the control group.

Foxp $3^{+}$was detected by immunohistochemistry in three groups, while the expression of Foxp $3^{+}$in the ginsenoside group is significantly up-regulated, but there is no significant difference compared with the negative control group, as shown in fig. 3 .
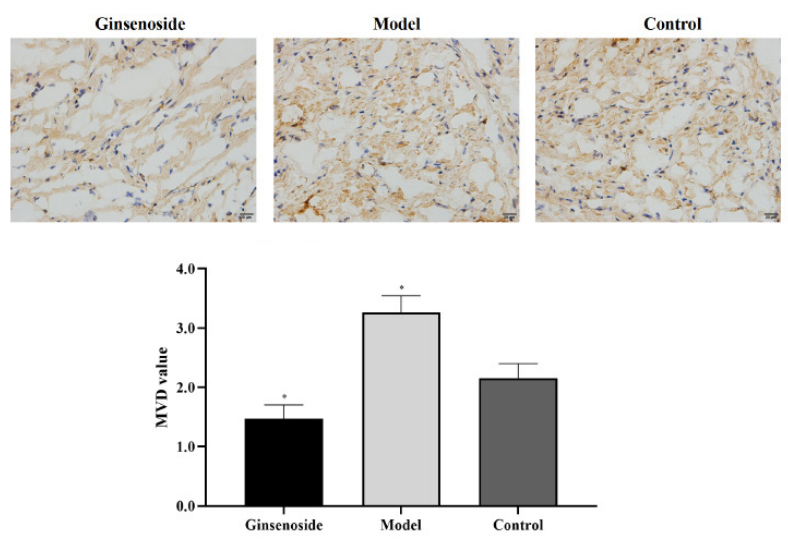

Fig. 1: Comparison of tumor microvessel density among three groups Note: *compared with control group, p<0.05, ( - ) Ginsenoside; ( 口 ) Model; ( a ) Control 


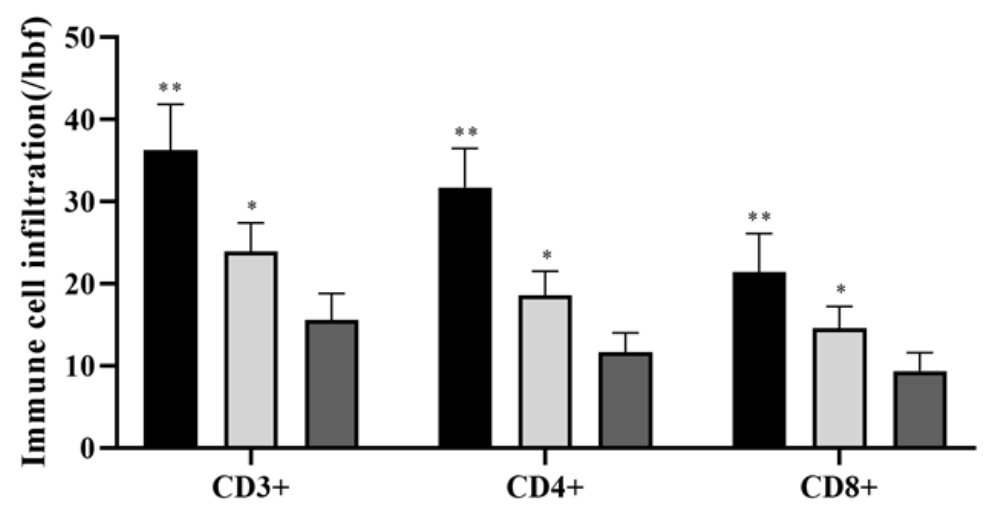

Fig. 2: Infiltration of $\mathrm{CD3}^{+}, \mathrm{CD}^{+}$and $\mathrm{CD8}^{+}$effector $\mathrm{T}$ lymphocytes

Note: *compared with control group, $\mathbf{p}<\mathbf{0 . 0 5}$; ** compared with control group, p<0.01, ( - ) Ginsenoside; ( 口) Model; ( 口) Control

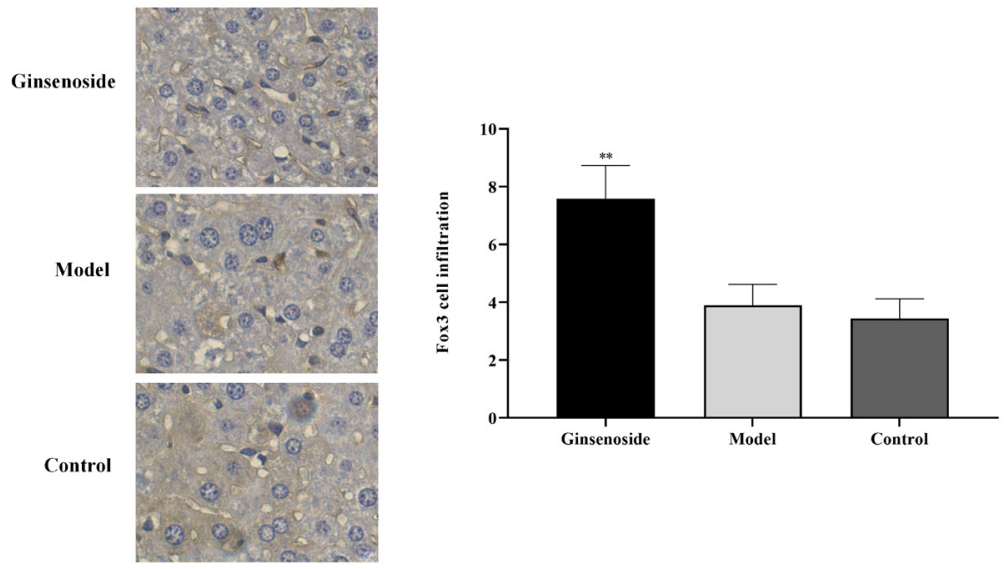

Fig. 3: Foxp3 ${ }^{+}$detection results of three study groups

Note: **compared with control group, p<0.01, p<0.01, ( ש ) Ginsenoside; ( • ) Model; (ש ) Control

The expression level of TGF- $\beta 1$ in the three groups was significantly different $(\mathrm{p}<0.05)$; the gray value of TGF- $\beta 1$ in the model group was lower than that in the control group, but the difference was not statistically significant $(p>0.05)$; the gray value of TGF- $\beta 1$ in the ginsenoside group was significantly lower than that in the model group $(\mathrm{p}<0.05)$, as shown in fig. 4 .

In the treatment group, there were 3 patients with $\mathrm{CR}$, 18 patients with PR, 7 patients with stable remission and 2 patients with progressive remission; in the control group, there were 10 patients with PR, 16 patients with stable remission and 4 patients with progressive remission. There was no CR in the control group and the effective rates of the two groups $(\mathrm{CR}+\mathrm{PR})$ were $70 \%(21 / 30)$ and $33.3 \%(10 / 30)$, respectively, with significant difference $(\mathrm{p}<0.05)$, as shown in Table 1 .

Two groups of patients before treatment have varying degrees of liver pain, abdominal distension, loss of appetite, fatigue symptoms; but the treatment group after treatment of patients with symptoms than before treatment were significantly improved $(p<0.05)$; the control group after treatment of patients with symptoms than before treatment, but the difference was not significant $(\mathrm{p}>0.05)$; the treatment group compared with the control group was significantly better than the control group, the difference was significant $(\mathrm{p}<0.05)$, as shown in Table 2.

After treatment, the adversereactions such as leukopenia, hemoglobin, platelets, nausea and vomiting, fever and so on in the treatment group were lower than those in the control group and the differences of leukopenia, nausea and vomiting between the two groups were significant $(p<0.05)$, indicating that Shenyi capsule can reduce the adverse reactions of chemotherapy, as shown in Table 3. 

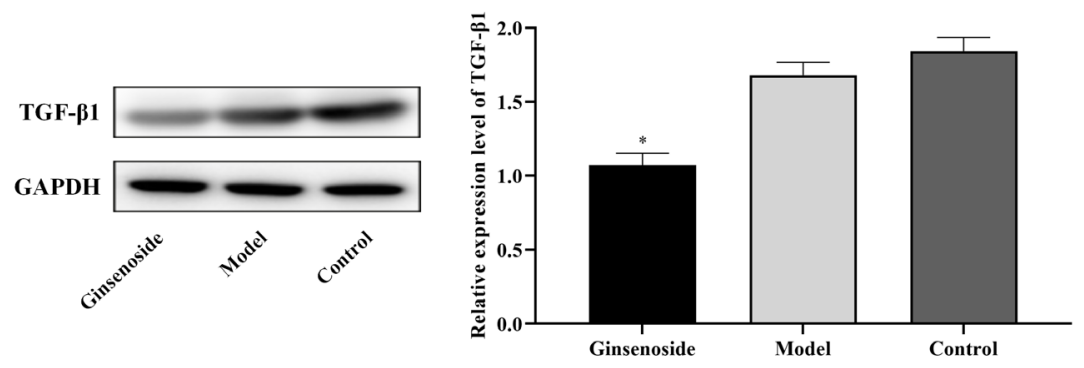

Fig. 4: Comparison of TGF- $\beta 1$ expression in three groups

Note: *compared with control group, p<0.05, ( - ) Ginsenoside; ( ( ) Model; ( ( ) Control

TABLE 1: SHORT TERM EFFICACY OF GINSENOSIDE

\begin{tabular}{lccccc}
\hline Group & $\begin{array}{c}\text { Complete } \\
\text { remission }\end{array}$ & Partial remission & Stable & Progress & $\begin{array}{c}\text { Effective rate of } \\
\text { treatment }\end{array}$ \\
\hline Treatment group & 3 & 18 & 7 & 2 & $21(70 \%)$ \\
Control group & 0 & 10 & 16 & 4 & $10(33.33 \%)$ \\
\hline
\end{tabular}

TABLE 2: COMPARISON OF SYMPTOM RELIEF BETWEEN TWO GROUPS BEFORE AND AFTER TREATMENT

\begin{tabular}{|c|c|c|c|c|c|c|}
\hline Group & $\mathrm{n}$ & Time & Pain & $\begin{array}{l}\text { Abdominal } \\
\text { distention }\end{array}$ & Loss of appetite & weakness \\
\hline \multirow[t]{2}{*}{ Treatment group } & 30 & $\begin{array}{l}\text { Before } \\
\text { treatment }\end{array}$ & $2.67 \pm 0.18$ & $3.24 \pm 0.21$ & $2.84 \pm 0.26$ & $2.94 \pm 0.25$ \\
\hline & 30 & After treatment & $0.73 \pm 0.06^{*}$ & $1.05 \pm 0.06^{*}$ & $0.93 \pm 0.11^{*}$ & $1.13 \pm 0.14^{*}$ \\
\hline \multirow[t]{2}{*}{ Control group } & 30 & $\begin{array}{l}\text { Before } \\
\text { treatment }\end{array}$ & $2.61 \pm 0.14$ & $3.17 \pm 0.18$ & $2.91 \pm 0.22$ & $3.03 \pm 0.37$ \\
\hline & 30 & After treatment & $1.96 \pm 0.11^{\#}$ & $2.59 \pm 0.23^{\#}$ & $2.17 \pm 0.18^{\#}$ & $2.48 \pm 0.26^{\#}$ \\
\hline
\end{tabular}

Note: *compared with before treatment, $p<0.05$; ${ }^{*}$ compared with after treatment, $p<0.05$

TABLE 3: COMPARISON OF ADVERSE REACTIONS BETWEEN THE TWO GROUPS

\begin{tabular}{|c|c|c|c|c|c|c|c|c|c|c|}
\hline \multirow[b]{2}{*}{ Adverse reactions } & \multicolumn{5}{|c|}{ Treatment group } & \multicolumn{5}{|c|}{ Control group } \\
\hline & I & II & III & IV & $\begin{array}{c}\text { Adverse } \\
\text { reaction rate }\end{array}$ & I & II & III & IV & $\begin{array}{c}\text { Adverse } \\
\text { reaction rate }\end{array}$ \\
\hline Leukopenia & 5 & 1 & 0 & 0 & $20.00 \%$ & 9 & 7 & 3 & 0 & $63.33 \%$ \\
\hline $\begin{array}{l}\text { Decrease of } \\
\text { hemoglobin }\end{array}$ & 6 & 3 & 0 & 0 & $30.00 \%$ & 6 & 5 & 0 & 0 & $36.67 \%$ \\
\hline Thrombocytopenia & 4 & 3 & 0 & 0 & $23.33 \%$ & 5 & 4 & 0 & 0 & $30.00 \%$ \\
\hline Nausea and vomiting & 7 & 4 & 1 & 0 & $40.00 \%$ & 17 & 8 & 3 & 1 & $96.67 \%$ \\
\hline
\end{tabular}

Liver cancer can be divided into secondary $\mathrm{HCC}$ and primary HCC. Secondary HCC, also known as metastatic HCC, refers to the invasion and metastasis of malignant tumors originated from multiple organs to the liver. Primary HCC is more common, refers to the malignant tumor originated from the liver epithelial or mesenchymal tissue ${ }^{[11]}$. At present, the pathogenesis of primary $\mathrm{HCC}$ is not clear and its risk factors mainly include hepatitis B virus infection, liver cirrhosis, family history of cancer, alcoholism, bad eating habits and so $o n^{[12]}$. The immune microenvironment of HCC patients is mainly composed of lymphocytes, fibroblasts, immune cells and hepatic stellate cells around HCC cells. When the immune microenvironment is normal, it can form a greater lethality to tumor cells and gradually improve the vital signs of patients. However, there is a strong inhibition of immune microenvironment 
in patients with $\mathrm{HCC}$, mainly because tumor cells destroy the immune microenvironment by secreting immunosuppressive factors in order to comply with their growth and metastasis and then make the disease worse ${ }^{[13]}$. Some studies have pointed out that ${ }^{[14]}$ hepatic artery embolization chemotherapy combined with immunotherapy can effectively improve the immune function of patients, reduce the level of serum tumor related indicators and improve the survival rate, indicating that the treatment of HCC from the immune microenvironment is worth exploring.

Ginsenoside is the main active component of Panax in Acanthopanax family, which has high activity in cancer prevention and treatment. Panaxazoxime can directly inhibit tumor growth by inducing apoptosis or differentiation, inhibit tumor metastasis, reverse drug resistance and improve the anti-tumor activity of chemotherapeutic drugs ${ }^{[15]}$. Ginseng soap camp is equivalent to the tonic medicine in traditional Chinese medicine, which plays the role of strengthening healthy and eliminating pathogenic factors.

Angiogenesis plays an extremely important role in tumor growth and distant metastasis. MVD is an indicator of angiogenesis and has a significant correlation with the prognosis of many tumors, including $\mathrm{HCC}^{[16]}$. In this study, compared with the control group and model group, MVD value in the ginsenoside group decreased significantly, suggesting that ginsenoside treatment has anti-tumor angiogenesis effect.

The regulatory effect of ginsenosides on immune system is mainly to stimulate the normalization of various changes of low immune function and prevent the adverse effects caused by the decline of immune function. Studies have found that ${ }^{[17]}$ ginsenoside Rh1 can directly promote the proliferation of spleen lymphocytes, down regulate the proliferation of $\mathrm{T}$ lymphocytes induced by concanavalin A (ConA), Rh1 can also significantly improve the phagocytic capacity of peritoneal macrophages, thus promoting the release of no, suggesting that the immunoregulation effect of Rg1 on the body may be the result of directly acting on spleen, lymphocytes and macrophages by promoting the metabolism of intestinal bacteria ${ }^{[18]}$.

The cellular immunity mediated by effector $T$ cells plays a very important role in the anti-tumor immune effect ${ }^{[19]}$. The level of $\mathrm{CD}^{+} \mathrm{T}$ cells is positively correlated with the prognosis of tumor ${ }^{[20]}$ and high levels of $\mathrm{CD}^{+}$ and $\mathrm{CD}^{+}$cells often predict high survival rate ${ }^{[21]}$. The results showed that the levels of $\mathrm{CD}^{+}, \mathrm{CD}^{+}$and
$\mathrm{CD}^{+} \mathrm{T}$ lymphocytes in tumor tissues after ginsenoside treatment were significantly higher than those in the control group and negative control group, indicating that ginsenoside can promote the infiltration of effector $\mathrm{T}$ lymphocytes, which is consistent with the existing research results ${ }^{[22]}$.

Regulatory $\mathrm{T}$ cells (Treg cells) are a kind of mature $\mathrm{T}$ cell subsets with immunomodulatory function ${ }^{[23,24]}$. Treg cells characterized by constitutive expression of CD25, Programmed cell Death 1 (PD-1), cytotoxic T-lymphocyte-associated protein 4 (CTLA-4), Foxp3 and other marker molecules play an important role in tumor peripheral immune tolerance ${ }^{[25,26]}$, among which Foxp 3 is the most important and widely studied, which is the key factor controlling Treg cell development and its functional effect. The research results of Huang et al. ${ }^{[27]}$ showed that larger tumors were often accompanied by regulatory $\mathrm{T}$ cell infiltration and the presence of these cells may reduce the effect of immunotherapy ${ }^{[28]}$. Our results showed that Foxp $3^{+}$cells could be detected in the control group, while the Foxp $3^{+}$cell count in the ginsenoside group was significantly increased, but compared with the negative control group, the Foxp $3^{+}$ cell change was not obvious. These data indicate that $\mathrm{Foxp}^{+}$regulatory $\mathrm{T}$ cells exist in rat $\mathrm{HCC}$ and ginsenoside can increase Foxp $3^{+}$cells. Ginsenoside cannot completely induce apoptosis of these regulatory T cells.

In this study, Shenyi capsule combined with chemoembolization was used to treat advanced primary HCC. Compared with the control group, the treatment group has obvious advantages in terms of short-term efficacy, symptom relief and adverse reactions before and after treatment. In terms of short-term efficacy, the effective rates of the treatment group and the control group were $70 \%(21 / 30)$ and $33.3 \%$ (10/30), respectively, with significant difference between the two groups $(p<0.05)$. In terms of symptom relief, the patients' self-conscious symptoms of the treatment group were significantly improved after treatment $(p<0.05)$; the efficacy of the treatment group was significantly better than that of the control group, with significant difference $(p<0.05)$. In terms of adverse reactions, the two groups of patients after treatment, leucopenia, hemoglobin decline, thrombocytopenia, nausea and vomiting, fever and other adverse reactions, the treatment group was lower than the control group, in which leucopenia; nausea and vomiting were significantly different between the two groups $(p<0.05)$. Therefore, Shenyi capsule combined with 
interventional therapy in the treatment of advanced primary HCC, not only has the effect of anti-tumor, but also can improve the quality of life of patients and has a good curative effect on the treatment of advanced primary HCC. After interventional therapy of HCC, vital energy is damaged. Traditional Chinese medicine has the function of mild and lasting effect, increasing efficiency and reducing toxicity. It cannot only restore vital energy, but also have synergistic effect after interventional therapy of HCC. The curative effect is remarkable, which is worthy of clinical use.

In conclusion, ginsenosides can induce lymphocyte infiltration and inhibit tumor angiogenesis in rat $\mathrm{HCC}$ model. In addition, ginsenoside not only has the effect of anti-tumor, but also can improve the quality of life of patients and has a good effect on the treatment of advanced primary HCC.

\section{Acknowledgments:}

This work was supported by The Pilot Gastric Cancer Project of Clinical Cooperation of Traditional Chinese and Western Medicine for Major and Difficult Diseases, The Open Projects of the Discipline of Chinese Medicine of Nanjing University of Chinese Medicine, The Subject of Academic priority discipline of Jiangsu Higher Education Institutions (No. ZYX03KF020), The National Administration of Traditional Chinese Medicine, 2019 Project of Building Evidence Based Practice Capacity for TCM (No. 2019XZZX-ZL003) and The Jiangsu Provincial Commission of Health and Family Planning (No. Q2017003). Yulan Wang and Jing Cai are contributed equally to this work. Peng Shu and Guangmei Chen are considered co-correspondings.

\section{Conflicts of interest:}

The authors declared no conflict of interest.

\section{REFERENCES}

1. Yuan JH, Yang F, Wang F, Ma JZ, Guo YJ, Tao QF, et al. A long noncoding RNA activated by TGF- $\beta$ promotes the invasionmetastasis cascade in hepatocellular carcinoma. Cancer cell 2014;25(5):666-81.

2. Xie F, Yuan Y, Xie L, Ran P, Xiang X, Huang Q, et al. miRNA320a inhibits tumor proliferation and invasion by targeting c-Myc in human hepatocellular carcinoma. Onco Targets Ther 2017; 10:885.

3. Wang F, Ying HQ, He BS, Pan YQ, Deng QW, Sun HL, et al. Upregulated IncRNA-UCA1 contributes to progression of hepatocellular carcinoma through inhibition of miR-216b and activation of FGFR1/ERK signaling pathway. Oncotarget 2015;6(10):7899-917.

4. Lu C, Liao Z, Cai M, Zhang G. MicroRNA-320a downregulation mediates human liver cancer cell proliferation through the Wnt $/ \beta$-catenin signaling pathway. Oncol Lett 2017;13(2):573-8.

5. Kasinski AL, Slack FJ. MicroRNAs en route to the clinic: progress in validating and targeting microRNAs for cancer therapy. Nat Rev Cancer 2011;11(12):849-64.

6. Shimizu K. Mechanisms of pancreatic fibrosis and applications to the treatment of chronic pancreatitis. J Gastroenterol 2008;43(11):823-32.

7. de Mello Coelho V, Bunbury A, Rangel LB, Giri B, Weeraratna A, Morin PJ, et al. Fat-storing multilocular cells expressing CCR5 increase in the thymus with advancing age: potential role for CCR5 ligands on the differentiation and migration of preadipocytes. Int J Med Sci 2010;7(1):1.

8. Son G, Hines IN, Lindquist J, Schrum LW, Rippe RA. Inhibition of phosphatidylinositol 3-kinase signaling in hepatic stellate cells blocks the progression of hepatic fibrosis. Hepatology 2009;50(5):1512-23.

9. Su YC, Lee CC, Kung JT. Effector function-deficient memory $\mathrm{CD}^{+} \mathrm{T}$ cells clonally expand in the liver and give rise to peripheral memory $\mathrm{CD}^{+} \mathrm{T}$ cells. J Immunol 2010;185(12):7498-506.

10. Lee Y, Friedman SL. Fibrosis in the liver: acute protection and chronic disease. Prog Mol Biol Transl Sci 2010;97:151-200.

11. Xia X, Li X, Feng G, Zheng C, Liang H, Zhou G. Intraarterial interleukin-12 gene delivery combined with chemoembolization: anti-tumor effect in a rabbit hepatocellular carcinoma (HCC) model. Acta Radiol 2013;54(6):684-9.

12. Xu L, Peng ZW, Chen MS, Shi M, Zhang YJ, Guo RP, et al. Prognostic nomogram for patients with unresectable hepatocellular carcinoma after transcatheter arterial chemoembolization. J Hepatol 2015;63(1):122-30.

13. Liang $\mathrm{B}$, Zheng $\mathrm{C}$, Feng $\mathrm{G}$, Wu $\mathrm{H}$, Wang $\mathrm{Y}$, Zhao $\mathrm{H}$, et al. Experimental evaluation of inhibitory effect of 10 -hydroxycamptothecin on hypoxia-inducible factor- $1 \alpha$ expression and angiogenesis in liver tumors after transcatheter arterial embolization. J Vasc Interv Radiol 2010;21(10):156572.

14. Chan SF, Wang HT, Huang KW, Torng PL, Lee HI, Hwang LH. Anti-angiogenic therapy renders large tumors vulnerable to immunotherapy via reducing immunosuppression in the tumor microenvironment. Cancer Lett 2012;320(1):23-30.

15. Jameel NM, Thirunavukkarasu C, Murase N, Cascio M, Prelich $\mathrm{J}$, Yang S, et al. Constitutive release of powerful antioxidantscavenging activity by hepatic stellate cells: Protection of hepatocytes from ischemia/reperfusion injury. Liver Transpl 2010;16(12):1400-9.

16. Zhou W, Li J, Li X, Yan Q, Zhou P. Development and validation of a reversed-phase HPLC method for quantitative determination of ginsenosides Rb1, Rd, F2 and compound $\mathrm{K}$ during the process of biotransformation of ginsenoside Rb1. J Sep Sci 2008;31(6-7):921-5.

17. Lee IK, Kang KA, Lim CM, Kim KC, Kim HS, Kim DH, et al. Compound $\mathrm{K}$, a metabolite of ginseng saponin, induces mitochondria-dependent and caspase-dependent apoptosis via the generation of reactive oxygen species in human colon cancer cells. Int J Mol Sci 2010;11(12):4916-31.

18. Cave M, Deaciuc I, Mendez C, Song Z, Joshi-Barve S, Barve $\mathrm{S}$, et al. Nonalcoholic fatty liver disease: Predisposing factors and the role of nutrition. J Nutr Biochem 2007;18(3):184-95.

19. Sun JY, Huang Y, Li JP, Zhang X, Wang L, Meng YL, et al. MicroRNA-320a suppresses human colon cancer cell proliferation by directly targeting $\beta$-catenin. Biochem Biophys Res Commun 2012;420(4):787-92. 
20. Wang Z, Li X. The role of noncoding RNA in hepatocellular carcinoma. Gland Surg 2013;2(1):25-9.

21. Zaman MS, Shahryari V, Deng G, Thamminana S, Saini S, Majid S, et al. Up-regulation of microRNA-21 correlates with lower kidney cancer survival. PloS One 2012;7(2):e31060.

22. Woo DK, Kim HS, Lee HS, Kang YH, Yang HK, Kim WH. Altered expression and mutation of $\beta$-catenin gene in gastric carcinomas and cell lines. Int J Cancer 2001;95(2):108-13.

23. De LCA, Romagnolo B, Billuart P, Renard CA, Buendia MA, Soubrane $\mathrm{O}$, et al. Somatic mutations of the beta-catenin gene are frequent in mouse and human hepatocellular carcinomas. Proc Natl Acad Sci U S A 1998;95(15):8847-51.

24. Fang Y, Feng Y, Wu T, Srinivas S, Yang W, Fan J, et al. Aflatoxin B1 negatively regulates $W n t / \beta$-catenin signaling pathway through activating miR-33a. PloS one 2013;8(8):e73004.

25. Faria M, Matos P, Pereira T, Cabrera R, Cardoso BA, Bugalho $\mathrm{MJ}$, et al. RAC1b overexpression stimulates proliferation and NF-kB-mediated anti-apoptotic signaling in thyroid cancer cells. PLoS One 2017;12(2):e0172689.
26. Harder JM, Libby RT. Deficiency in Bim, Bid and Bbc3 (Puma) do not prevent axonal injury induced death. Cell Death Differ 2013;20(1):182.

27. Huang JL, Zheng $\mathrm{L}, \mathrm{Hu} \mathrm{YW}$, Wang Q. Characteristics of long non-coding RNA and its relation to hepatocellular carcinoma. Carcinogenesis 2014;35(3):507-14.

28. Li C, Feng Y, Coukos G, Zhang L. Therapeutic microRNA strategies in human cancer. AAPS J 2009;11(4):747-57.

This is an open access article distributed under the terms of the Creative Commons Attribution-NonCommercial-ShareAlike 3.0 License, which allows others to remix, tweak, and build upon the work non-commercially, as long as the author is credited and the new creations are licensed under the identical terms

This article was originally published in a special issue, "Diagnostic and Therapeutic Advances in Biomedical Research and Pharmaceutical Sciences"

Indian J Pharm Sci 2021:83(5) spl issue "161-168" 